\title{
Effects of Early and Late Parenteral Nutrition on Clinical Outcomes in Very Low Birth Weight Preterm Infants: A Systematic Review and Meta- analysis
}

Kotiya $\mathbf{P}$ and Xueping Zhu*

Department of Neonatology, Children's Hospital of Soochow University, Suzhou, Jiangsu, P.R. China

\begin{abstract}
Background: Parenteral nutrition (PN) provided to the very low birth weight (VLBW) premature infants should be resulted in gradually development as of the other fetuses following the same gestational age. Even after providing the proven beneficial parenteral nutrition supplements, VLBW infants are often presents with the unfavorable results; the main reason behind it is the decision of the administration of parenteral nutrition, whether it is in early life or later days.

Objective: The objective of this study is to explore the effect of early and late parenteral nutrition in the VLBW premature infants. In this study we hypothesize that early parenteral nutrition is associated with comparatively beneficial outcomes.

Methods: The PubMed (PubMed Central), Medline, and Google Scholar databases were searched from 1993 to 2013. Methodological quality assessment was based on the PRISMA guidelines. Data analysis were conducted with RevMan 5.3

Results: Ten studies including thirteen trials met our inclusion criteria. The aggregate results of trials showed that early parenteral nutrition was well tolerated by VLBW preterm infants and there was significant reduction in sepsis (RR=0.82, 95\% Cl=0.69 0.98, $\mathrm{P}=0.03$ )

Conclusion: Comparison made between the patients provided early and late parenteral nutrition, the development and reduction of clinical disease were significantly lower in the early parenteral nutrition group. The cost-effectiveness of these preparations, however, needs to be further explored. The poor qualities of studies call into a question and robustness of the analysis.
\end{abstract}

Keywords: Early; late; nutrition; lipid emulsion; parenteral nutrition; preterm; infants

\section{Introduction}

Parenteral nutrition (PN) in VLBW premature neonates is one of the most important treatment regimes in the early life. Though it is proved as a lifesaving option, but still there are several opinions on its administration. Some researches support the early administration, whereas other supports late one. In this study we hypothesize that early PN has associated with comparative beneficial improvements in the clinical outcomes. We try to explore the effect of early and late administration of PN on the account of different clinical outcomes, such as sepsis, Broncho-Pulmonory Disease (BPD), Intraventricular Haemorrhage (IVH), Mortality, Patent Ductus Arteriosus (PDA), Necrotizing Entercolitis (NEC) and Retinopathy of Prematurity (ROP).

\section{Materials and Method}

For the current review, the Preferred Reporting Items for Systemic Review and Meta-Analysis (PRISMA) statements were followed.

\section{Search strategy}

We retrieved relevant articles published between 1993 and 2013 using the following key terms "neonates", "infants", "very low birth weight”, "premature” , "preterm”, "Early Infusion”; "parenteral” or "enteral nutrition", "infusion", "intravenous", and "IV administration dosage". The searches were limited to human trials, and the language was limited to English during the search. Ethical approval was not required for inclusion in the present review.

\section{Data collection}

The author extracted, assessed, and coded all data from each study by using a form that was designed specifically for this review. For each study, entered the final data into RevMan (RevMan version 5.3, 2014; Copenhagen: The Nordic Cochrane Centre, The Cochrane Collaboration).

The inclusion and exclusion criteria were as follows.

\section{Inclusion criteria}

1. Study design: we selected randomized control trials set up with parallel control groups excluding self-control or crossover trials.

2. Types of patients: Premature neonates with gestation age (GA) 24-36 weeks and those having birth weight between 600-1500 g.

3. Intervention: patients administered with early $\mathrm{PN}$.

\section{Exclusion criteria}

1. Case reports, case series, and cohort trials.

2. Adult and animal experimental trials.

*Corresponding author: Xueping Zhu, Department of Neonatology, Children's Hospital of Soochow University, Suzhou 215003, Jiangsu, China, Tel: +8613073304816; E-mail: zhuxueping4637@hotmail.com

Received July 03, 2015; Accepted August 27, 2015; Published August 31, 2015

Citation: Kotiya P, Zhu X (2015) Effects of Early and Late Parenteral Nutrition on Clinical Outcomes in Very Low Birth Weight Preterm Infants: A Systematic Review and Meta-analysis. J Neonatal Biol 4: 191. doi:10.4172/2167-0897.1000191

Copyright: ( 2015 Kotiya P, et al. This is an open-access article distributed under the terms of the Creative Commons Attribution License, which permits unrestricted use, distribution, and reproduction in any medium, provided the original author and source are credited. 
3. Trials in which the number of participants, duration of trial, and study location were not mentioned.

4. Trials lacking sufficient data.

5. Trials that were not RCTs.

Definition of early and late PN: Early parenteral nutrition refers to providing the parenteral nutrition within postnatal 24 hours and after that is referred as the late one. And the amino acids and fatty acids are provided together in a combination, postnatal 0-24 hours for the early nutrition group and 24 hours later for the late one.

\section{Clinical outcomes}

Primary outcome: sepsis.

Secondary outcomes: BPD, NEC, IVH, ROP, PDA and mortality.

\section{Methodological quality assessment}

The methodological quality assessment was based on the Cochrane handbook and the score scale of Jadad et al., (Table 1) [1]. The quality of the RCTs was assessed by authors by using the Jadad criteria (0-5 pointing rating scale, with 5 as the maximum score) [1].

\section{Statistical analyses}

Measure of treatment effect and assessment of heterogeneity: Heterogeneity was assessed using the $\mathrm{I}^{2}$ measurement, with $\mathrm{I}^{2}>0.3$ indicating significant heterogeneity. We combined data from all trials using the Mantel-Haenszel model when heterogeneity did not exist between aggregated trials. For dichotomous outcomes such as sepsis, NEC, BPD, PDA, ROP, IVH and mortality, a risk ratio (RR) and the corresponding $95 \%$ confidence interval (CI) were calculated. A RR and $95 \% \mathrm{CI}<1$ favours early $\mathrm{PN}$ group, whereas an RR and 95\% CI $>1$ favour the late PN group. There is no statistical significance when RR equals 1 or its $95 \%$ CI crosses 1 between the groups.

Whenever heterogeneity was found, the sources were analysed and trials were considered for stratified analyses. Trials were sub-grouped according to their characteristics, such as treatment effect, progression of disease, and change in nutritional status. Review Manager 5.3 statistical software (Cochrane Collaboration) was used for the metaanalysis.

\begin{tabular}{|c|c|c|c|}
\hline First author & Year & $\mathbf{N}$ & Population \\
\hline Leaf [4] & 2012 & 402 & $\begin{array}{l}\text { Premature infants }<34 \text { weeks of GA and BW } \\
<1250 \mathrm{~g}\end{array}$ \\
\hline Davey [5] & 1994 & 60 & Premature infants with $\mathrm{BW}<1500 \mathrm{~g}$ \\
\hline Ibrahim [6] & 2004 & 32 & $\begin{array}{l}\text { Premature infants }<27 \text { weeks } \mathrm{GA} \text { and } \mathrm{BW} \\
<1000 \mathrm{~g}\end{array}$ \\
\hline Brownlee [7] & 1993 & 129 & Prematureinfants $24-36$ weeks GA \\
\hline Wilson [8] & 1997 & 125 & Premature infants BW $<1500 \mathrm{~g}$ \\
\hline Blanco [9] & 2008 & 61 & $\begin{array}{l}\text { Premature infants }<26.5 \text { weeks } \mathrm{GA} \text { and } \mathrm{BW}< \\
800 \mathrm{~g}\end{array}$ \\
\hline Blanco [10] & 2010 & 61 & $\begin{array}{l}\text { Premature infants }<26.5 \text { weeks } \mathrm{GA} \text { and } \mathrm{BW}< \\
800 \mathrm{~g}\end{array}$ \\
\hline Blanco [11] & 2012 & 61 & $\begin{array}{l}\text { Premature infants }<26.5 \text { weeks } \mathrm{GA} \text { and } \mathrm{BW}< \\
800 \mathrm{~g}\end{array}$ \\
\hline Valentine [12] & 2009 & 440 & $\begin{array}{l}\text { Premature infants }<30 \text { weeks } \mathrm{GA} \text { and BW } \\
<1250 \mathrm{~g}\end{array}$ \\
\hline Kostapoulous [13] & 2006 & 108 & $\begin{array}{l}\text { Premature infants }<26.5 \text { weeks } \mathrm{GA} \text { and BW } \\
<900 \mathrm{~g}\end{array}$ \\
\hline Gilbertson [14] & 1991 & 29 & Premature infants $\mathrm{BW}<1500 \mathrm{~g}$ \\
\hline Sosenko [15] & 1993 & 133 & Premature infants BW $600-1000 \mathrm{~g}$ \\
\hline
\end{tabular}

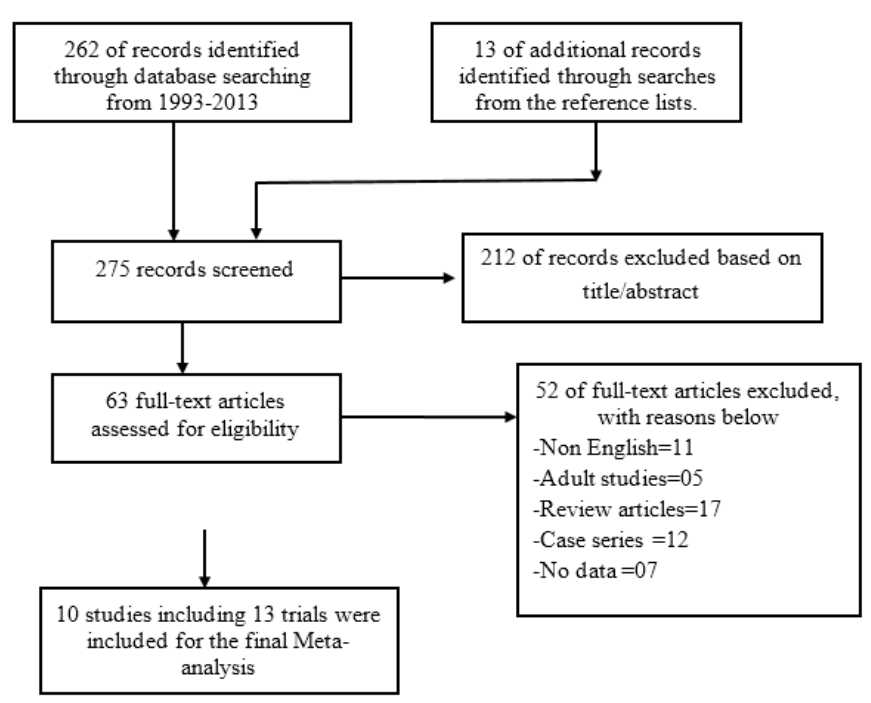

Figure 1: Selection of studies.

Assessment of reporting biases: To detect reporting bias, a funnel plot was constructed. However, if there were too few trials to permit proper evaluation of reporting bias, we used Begg and Egger tests to evaluate the potential asymmetry of the funnel plot.

\section{Results}

\section{Study identification and selection}

Our search returned 275 relevant titles, abstracts, and articles. Figure 1 shows the details of the trial selection process and the reasons for exclusion of some studies. Finally, 10 papers including 13 trials that met all inclusion criteria were selected for meta-analysis. Wilson et al., reported on two studies on different birth weight neonates [2].

\section{Characteristics of the studies}

The inclusion of preterm infants was on the basis of gestational age in 1 trial, birth weight in 4 trials and of both gestation and birth weight in 7 trials [3-15]. Milk feeding, Lipid emulsions with medium chain triglycerides (MCT), amino acids (AA), soybean oil, MCT and soybean oils, AA and glucose, were compared between the intervention and control. The only difference between the intervention and control is the early and late administration of administration along with differences in dosage.

In six trials [6, 9-13], the intervention group and control group received amino acid. In two trials [14,15] the intervention group and the control group received soy emulsions. In one trial (4) the intervention and control group received the PN. In one trial the intervention and control group received the milk feeding [5]. In one trial the intervention and control group received soy oil and MCT. In one trial the intervention and control group received the PN $[4,8]$. The baseline characteristics and outcome measures of these trials are shown in Table 1, and a total of 1519 infants were included in this analysis. The characteristics of included trials are listed in Table 1 and 2.

\section{Comparison of outcome measures}

Incidence of BPD: Eight trials involving 1169 patients evaluated the impact of different lipid emulsions on incidence of BPD [6-8, 1215]. The result favors the early administration of amino acid after birth over the delayed administration. Use of soy and MCT in early hours 
Citation: Kotiya P, Zhu X (2015) Effects of Early and Late Parenteral Nutrition on Clinical Outcomes in Very Low Birth Weight Preterm Infants: A Systematic Review and Meta-analysis. J Neonatal Biol 4: 191. doi:10.4172/2167-0897.1000191

Pge 3 of 7

is also useful. Whereas it's delayed use is associated with the adverse effects $[\mathrm{RR}=0.87,95 \% \mathrm{CI}=0.55 \sim 1.38, \mathrm{P}=0.55]$. There was significant heterogeneity observed across the trials $[\mathrm{P}=0.00001]$ (Figure 2).

Incidence of NEC: Eight trials [4,5,8,12-16] involving 1473 patients evaluated the impact of lipid emulsion on the incidence of NEC. the result of trials showed the positive effect of late feeding of milk, whereas majority trials favors the use of amino acids, MCT, soy emulsion and glucose on the early life with the positive outcomes. There was no statistical significance $[\mathrm{RR}=0.87,95 \% \mathrm{CI}=0.53 \sim 1.44, \mathrm{P}=0.59$; (Figure $3)$. The test for heterogeneity was not significant $[\mathrm{P}=0.14]$.
Incidence of PDA: Seven trials involving 1304 patients evaluated the impact of lipid emulsion on the incidence of PDA. The trials showed the mixed effects, some trials shows the neutral effects in between the early and late administrations. But the trials with large group of patients favors the early administration of amino acids, soy emulsion, amino acid and glucose over the delayed trials. There was no statistical significance $[R R=0.85,95 \% \mathrm{CI}=0.55-1.30, \mathrm{P}=0.45$; (Figure 4). The test for heterogeneity was highly significant $[\mathrm{P}=0.00001]$.

Mortality: Nine trials involving 964 patients evaluated the impact of lipid emulsion on the mortality. The majority of trails described that

\begin{tabular}{|c|c|l|}
\hline First author & Score* $^{*}$ & Intervention and duration \\
\hline Leaf [4] & 3 & start PN within 24 and 48 hours vs. $10-11$ days after birth \\
\hline Davey [5] & 2 & start milk feeding at day 2 vs. day 5 \\
\hline Ibrahim [6] & 3 & Start $3.5 \mathrm{~g} / \mathrm{kg} / \mathrm{d}$ AA 2 hrs after birth vs. $5-10 \%$ glucose during first 48 hours then $2 \mathrm{~g} / \mathrm{kg} / \mathrm{d}$ of $\mathrm{AA}$ after 48 hours. \\
\hline Brownlee [7] & 1 & start TPN with soy-oil emulsion and AA within 36 hours vs. at day 6 \\
\hline Wilson [8] & 3 & start lipid $\mathrm{MCT}+$ soy-oil emulsion at day 2 and $\mathrm{AA}<12$ hours vs. start lipid MCT+ soy-oil emulsion at day 5 and at day 3 \\
\hline Blanco [9] & 2 & start AA $2 \mathrm{~g} / \mathrm{kg} / \mathrm{d}<24$ hours vs. AA $0.5 \mathrm{~g} / \mathrm{kg} / \mathrm{d}<24-36$ hours \\
\hline Blanco [10] & 2 & start AA $2 \mathrm{~g} / \mathrm{kg} / \mathrm{d}<24$ hours vs. AA $0.5 \mathrm{~g} / \mathrm{kg} / \mathrm{d}<24-36$ hours \\
\hline Blanco [11] & 2 & start AA $2 \mathrm{~g} / \mathrm{kg} / \mathrm{d}<24$ hours vs. AA $0.5 \mathrm{~g} / \mathrm{kg} / \mathrm{d}<24-36$ hours \\
\hline Valentine [12] & 4 & start AA $<24$ hours vs. AA $>24$ hours \\
\hline Kostapoulous [13] & 2 & start AA $1 \mathrm{~g} / \mathrm{kg} / \mathrm{d}<6$ hours vs. AA $1 \mathrm{~g} / \mathrm{kg} / \mathrm{d} 12-30$ hours \\
\hline Gilbertson [14] & 1 & start lipid soy-oil emulsion at day 1 and $v$ s. at day 8 \\
\hline Sosenko [15] & 3 & start lipid soy-oil emulsion $<12$ hours vs. after day 7 \\
\hline
\end{tabular}

*Quality was assessed using the Jadad (18) criteria (0-5-point rating scale, with 5 as the maximum score)

Table 2: Characteristics of studies.

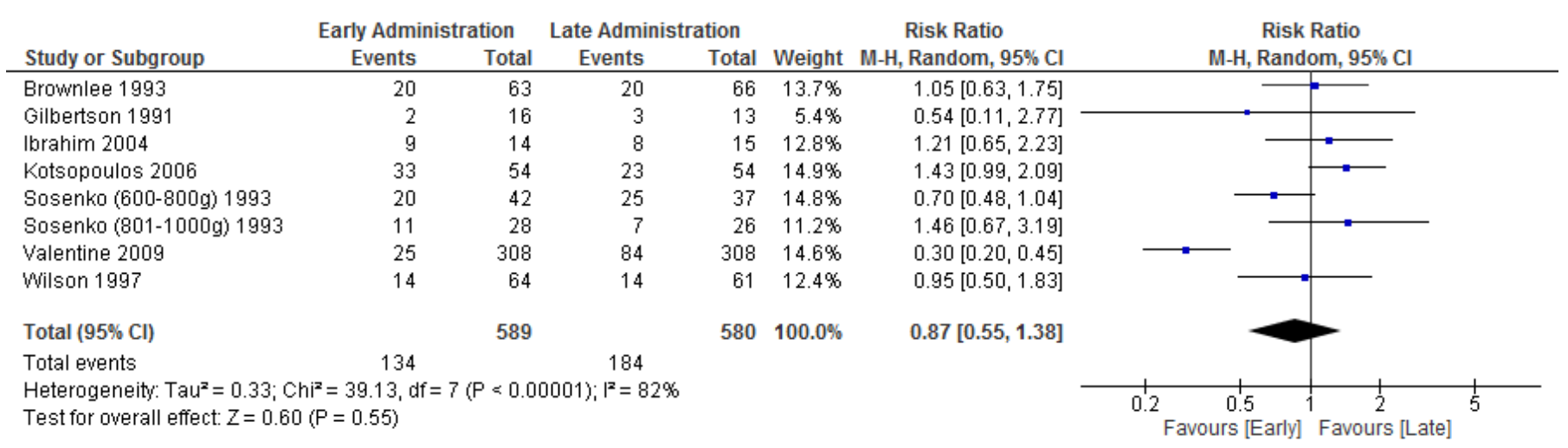

Figure 2: Meta-analysis of incidence of BPD.

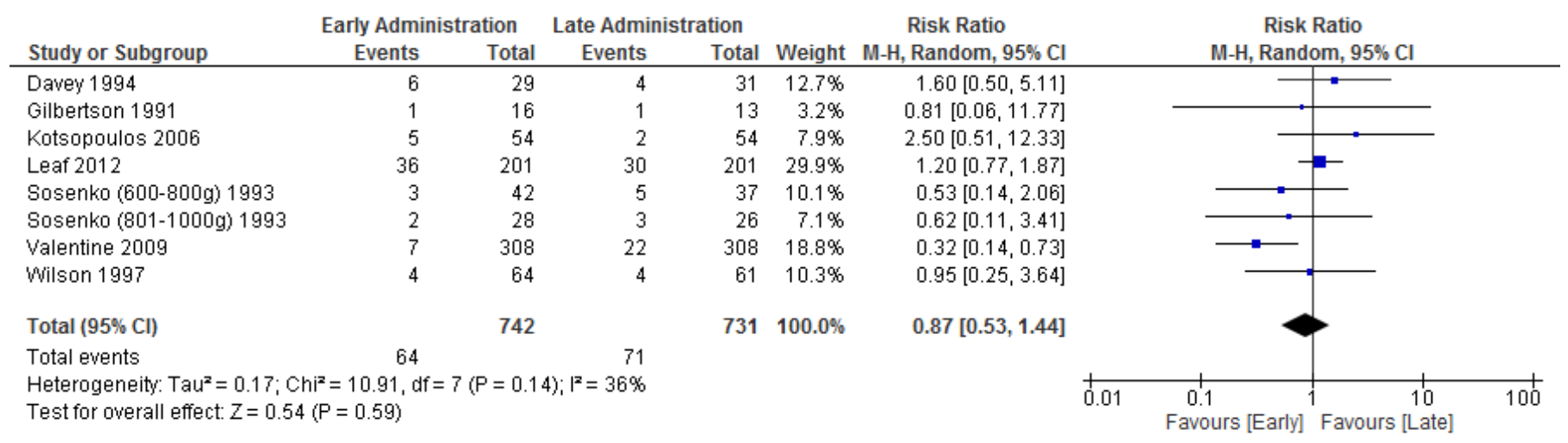

Figure 3: Meta-analysis of NEC. 
Citation: Kotiya P, Zhu X (2015) Effects of Early and Late Parenteral Nutrition on Clinical Outcomes in Very Low Birth Weight Preterm Infants: A Systematic Review and Meta-analysis. J Neonatal Biol 4: 191. doi:10.4172/2167-0897.1000191

Pge 4 of 7

the early administration of amino acids, MCT, glucose and soy oil are associated with less number of death of the patients where as their late administration is associated with increased number of deaths. There was no statistical significance $[\mathrm{RR}=1.03,95 \% \mathrm{CI}=0.71 \sim 1.49, \mathrm{P}=0.99$; (Figure 5). The test for heterogeneity was not significant $[\mathrm{P}=0.29]$.

Incidence of sepsis: Seven trials [4,6,8,13-15] involving 821 patients evaluated the impact of lipid emulsion on the incidence of Sepsis. There were the extremely effective improvement observed in the group provided with the early administration of amino acids, MCT, glucose and soy emulsions, whereas their late administration has no effect. There was statistical significance $[\mathrm{RR}=0.82,95 \% \mathrm{CI}=0.69 \sim 0.98$, $\mathrm{P}=0.03$; (Figure 6). The test for heterogeneity was not significant $[\mathrm{P}=0.16]$.

Incidence of IVH: Five trials involving 807 patients evaluated the impact of lipid emulsion on the incidence of IVH. There were extremely positive results obtained in the group provided with administration of soy oil emulsion, amino acids and MCT in the early life hours. Whereas there were no positive result obtained on the late parenteral nutrition group. There was highly statistical significance $[\mathrm{RR}=0.64,95 \% \mathrm{CI}=$ $0.50 \sim 0.82, \mathrm{P}=0.0004$; (Figure 7 ). The test for heterogeneity was not significant $[\mathrm{P}=0.47]$.

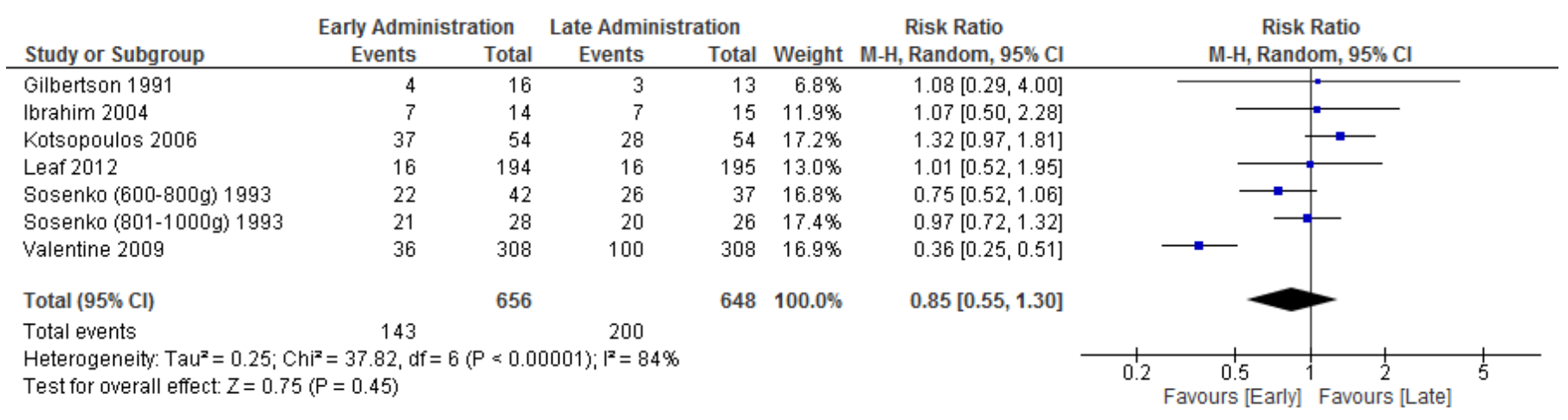

Figure 4: Meta-analysis of PDA

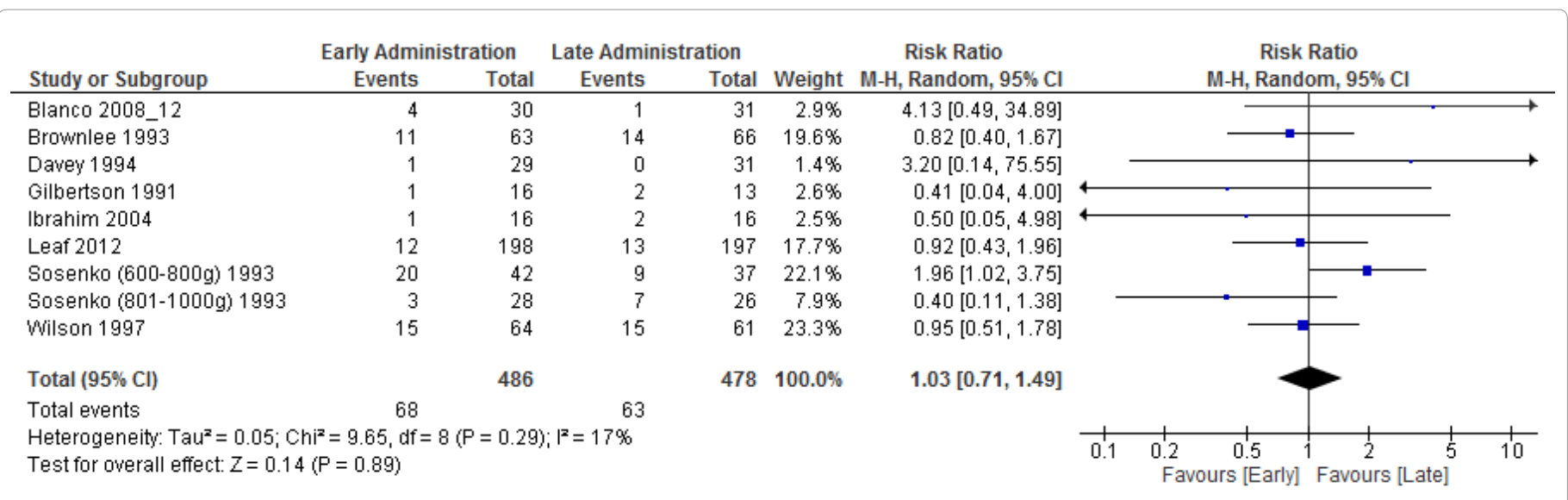

Figure 5: Meta-analysis of Mortality.

\begin{tabular}{|c|c|c|c|c|c|c|c|c|}
\hline \multirow[b]{2}{*}{ Study or Subgroup } & \multicolumn{2}{|c|}{ Early Administration } & \multicolumn{2}{|c|}{ Late Administration } & \multirow[b]{2}{*}{ Weight } & \multirow{2}{*}{$\begin{array}{c}\text { Risk Ratio } \\
\text { M-H, Random, } 95 \% \mathrm{Cl}\end{array}$} & \multirow{2}{*}{\multicolumn{2}{|c|}{$\begin{array}{c}\text { Risk Ratio } \\
\text { M-H, Random, } 95 \% \mathrm{Cl}\end{array}$}} \\
\hline & Events & Total & Events & Total & & & & \\
\hline Gilbertson 1991 & 2 & 16 & 5 & 13 & $1.4 \%$ & $0.33[0.07,1.41]$ & $\longleftarrow$ & \\
\hline Ibrahim 2004 & 6 & 14 & 7 & 15 & $4.3 \%$ & $0.92[0.41,2.07]$ & & \\
\hline Kotsopoulos 2006 & 16 & 54 & 30 & 54 & $10.6 \%$ & $0.53[0.33,0.86]$ & & \\
\hline Leaf 2012 & 55 & 198 & 69 & 199 & $20.1 \%$ & $0.80[0.60,1.08]$ & & \\
\hline Sosenko (600-800g) 1993 & 34 & 42 & 33 & 37 & $30.4 \%$ & $0.91[0.75,1.09]$ & & \\
\hline Sosenko (801-1000g) 1993 & 19 & 28 & 16 & 26 & $13.8 \%$ & $1.10[0.74,1.64]$ & & \\
\hline Wilson 1997 & 32 & 64 & 40 & 61 & $19.3 \%$ & $0.76[0.56,1.03]$ & & \\
\hline Total $(95 \% \mathrm{Cl})$ & & 416 & & 405 & $100.0 \%$ & $0.82[0.69,0.98]$ & & \\
\hline Total events & 164 & & 200 & & & & & \\
\hline \multicolumn{7}{|c|}{$\begin{array}{l}\text { Heterogeneity: } \operatorname{Tau}^{2}=0.02 ; \mathrm{Chi}^{2}=9.20, \mathrm{df}=6(P=0.16) ;\left.\right|^{2}=35 \% \\
\text { Test for overall effect: } Z=2.20(P=0.03)\end{array}$} & 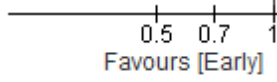 & $\begin{array}{cc}1.5 & 2 \\
\text { Favours [Late] }\end{array}$ \\
\hline
\end{tabular}

Figure 6: Meta-analysis of Sepsis. 
Incidence of ROP: Four trial involving 199 patients evaluated the impact of lipid emulsion on the incidence of ROP. The results shows that early administration of amino acid, along with soy emulsion is associated with less incidence of ROP, whereas late administration has no positive effects, In a trial [15], early PN is useful in low birth weight premature whereas as in other age group (801-1000g) late administration is favorable. There was no statistical significance $[\mathrm{RR}=0.99,95 \% \mathrm{CI}=0.49 \sim 0.01, \mathrm{P}=2.00$; Figure 8]. The test for heterogeneity was not significant $[\mathrm{P}=0.52]$.

\section{Discussion}

The use of early PN is quite common nowadays and its demand is rapidly increasing for the pediatric population especially in preterm neonates [17]. In this systematic review, the benefits and harmful effects of lipid emulsion has been described on the account of clinical outcomes, by the introduction of lipid in early and late life days.

The use of lipid emulsions are valuable but have been limited by the different opinions in the lipid tolerance in infants In addition the time of infusion varies from place to place, which also make a big difference in the available results. Lipid emulsion provides the energy to the infants at the initial stage and fatty acid plays a major role in the maturation of organs $[1,6]$. In the outcomes like sepsis the trials unsurprisingly favors the early parenteral nutrition, the main reason behind that is shorter duration of supplements is the initial part of infants stay moreover it delivers the adequate nutrition which is essential to meet the need. Whereas the $\mathrm{PN}$ of longer duration is associated with many side effects [16].

For the outcomes like bronchopulmonary dysplasia out of eight included studies, the four studies favor early PN. Sosenko et al., described that early PN in premature infants with group of $601-800 \mathrm{~g}$, the early PN is well tolerated but in the group of 801-1000 gms, it is not tolerated. In the same manner studies like Gilbertson, Valentine, and Wilson also favors the early PN $[8,12,14,15]$.
The premature are prone to be get affected by BPD. Its recovery occurs gradually after a stable treatment until the maturation of lungs. It is reported that the most of the malnourished premature infant often present with the worsening of symptoms, because of inflammation. Another important cause for the worsening of the BPD is continuous oxygen therapy for the long period of time, if premature infants were provided with high level oxygen that can lead to respiratory distress syndrome (RDS). The artificial ventilators provides oxygen directly to the lungs forcefully, and the lungs of premature babies are incompetent for it $[18,19]$.

Regarding NEC, the majority of included trials favors the early PN. Davey et al., used the formula fed nutrition administration so it is not beneficial. NEC is the most common morbidity in the premature infants [5]. It usually develops with in the first two week of the birth. The majority of premature infants are the sufferers of NEC. It occurs due to lack of oxygen supplements in the early life, another cause is the under developed intestine, in both cases the premature babies are common. It is also a leading cause of mortality in premature infants $[20,21]$. Infants provided with early PN can attain the nourishment which their intestine in unable to absorb. Sosenko in both groups are well tolerated, whereas other studies such as Wilson et al., [8], Valentine et al., [12] and Gilbertson et al., [14] highly favors the early PN.

Evidences regarding the PDA, it is another anomaly which occurs in the premature infants that affect the lung maturation because of less oxygen rich blood supplement in the body [21]. In few studies like Sosenko, leaf and valentine early $\mathrm{PN}$ is well tolerated, because if the early $\mathrm{PN}$ is provided it helps in the maturation of lungs and the proper supplement of oxygen. The majority of studies support the early PN [20].

On the account of mortality, most of the studies favors the use of early PN, whereas a few studies favors the use of late PN. In the studies like Brownlee, Davey, Ibrahim, Leaf, Sosenko and Wilson, the

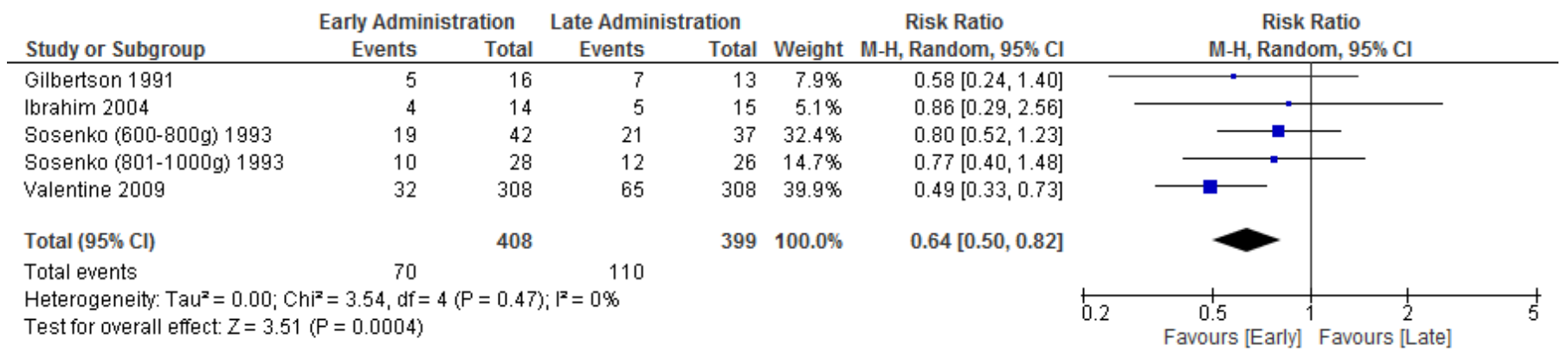

Figure 7: Meta-analysis of IVH.

\begin{tabular}{|c|c|c|c|c|c|c|c|c|c|c|}
\hline \multirow[b]{2}{*}{ Study or Subgroup } & \multicolumn{2}{|c|}{ Early Administration } & \multicolumn{2}{|c|}{ Late Administration } & \multirow[b]{2}{*}{ Weight } & \multirow{2}{*}{$\begin{array}{c}\text { Odds Ratio } \\
\text { M-H, Random, } 95 \% \mathrm{Cl}\end{array}$} & \multirow{2}{*}{\multicolumn{4}{|c|}{$\begin{array}{c}\text { Odds Ratio } \\
\text { M-H, Random, } 95 \% \mathrm{Cl}\end{array}$}} \\
\hline & Events & Total & Events & Total & & & & & & \\
\hline Gilbertson 1991 & 0 & 16 & 1 & 13 & $4.5 \%$ & $0.25[0.01,6.74]$ & $\longleftarrow$ & & & \\
\hline Ibrahim 2004 & 2 & 14 & 3 & 14 & $12.6 \%$ & $0.61[0.09,4.37]$ & & & & \\
\hline Sosenko (600-800g) 1993 & 31 & 42 & 29 & 37 & $44.8 \%$ & $0.78[0.27,2.20]$ & & & & \\
\hline Sosenko (801-1000g) 1993 & 20 & 28 & 15 & 26 & $38.1 \%$ & $1.83[0.59,5.68]$ & & & & \\
\hline Total $(95 \% \mathrm{Cl})$ & & 100 & & 90 & $100.0 \%$ & $0.99[0.49,2.00]$ & & & & \\
\hline Total events & 53 & & 48 & & & & & & & \\
\hline \multicolumn{7}{|c|}{$\begin{array}{l}\text { Heterogeneity: } \text { Tau }^{2}=0.00 ; \mathrm{Chi}^{2}=2.25, \mathrm{df}=3(\mathrm{P}=0.52) ; \mathrm{I}^{2}=0 \% \\
\text { Test for overall effect: } Z=0.02(P=0.99)\end{array}$} & 0.01 & $\begin{array}{c}0.1 \\
\text { Favours [Early] }\end{array}$ & $\begin{array}{c}10 \\
\text { Favours [Late] }\end{array}$ & 100 \\
\hline
\end{tabular}

Figure 8: Meta-analysis of ROP 
Citation: Kotiya P, Zhu X (2015) Effects of Early and Late Parenteral Nutrition on Clinical Outcomes in Very Low Birth Weight Preterm Infants: A Systematic Review and Meta-analysis. J Neonatal Biol 4: 191. doi:10.4172/2167-0897.1000191

early PN is recommended. Regarding sepsis the majority of the studies supported the early PN group. There is enough evidence to support by the mentioned studies. The main reason behind that is as long as infants are supplied with the nourishment in the early times, the maturation of organs simultaneously takes place. Whether in the late PN groups the maturation of organ is not fully occur simultaneously due to lack of nourishment, which make easily prone to get affected from the infections that further lead to infections [21-26].

Regarding IVH, is reported to often get worsen after an infant affected from ARDS. Early PN is highly favorable in the prevention of IVH, the five trials that included in exploring this clinical outcome favors the early $\mathrm{PN}[27,28]$. In premature infants the blood vessels are immature at birth and retina produces abnormal level of various growth factors that are important for the eye development such as Vascular Endothelial Growth Factor (VEGF) to produce more blood vessels [29-31]. However the resulting vessels are abnormal and may lead to the bleeding and ultimately detachment. Out of four trials, majority of trials supported the early PN whereas one trial Sosenko et al, supported the late PN [15].

\section{Limitations of this review}

The common limitation was the study were based on the low scale population and the described quality were not too high. There was inconsistency of data in the present studies. Most of the included studies having less patients. A general limitation of the present review is that studies were included with clinical data, not with other hospital based data such as growth, respitaoty support, weigt gain, weight regain, duration of hospitalization.

\section{Conclusion}

In conclusion, the result of the present review, although subject to some limitations, promotes the use of early parenteral nutrition for the outcomes such as sepsis. The review did not provide any evidence that proves that early parenteral nutrition is associated with enhancement of mortality or morbidity. The present review supports the use of short term nutrition over the long term parenteral nutrition. In future, the additional researches efforts should focus on the optimum composition and effect of long term parenteral nutrition further need to be explored.

\section{Acknowledgments}

This research was supported by grants from the Suzhou Science and Technology Development Project (No. SYS201136, SYS201440), the Natural Science Foundation Project of Jiangsu Province (No. BK20141183), the Research Project of Department of Health of Jiangsu Province (No. H201316), the 135 Project of Department of Health of Jiangsu Province (No. RC2007076), and a research project of the Suzhou Key Laboratory of Children's Developmental Brain Injury Prevention and Care (No. SZS201108). We gratefully acknowledge all members of the laboratory for sharing reagents and advice.

\section{References}

1. Jadad AR, Moore RA, Carroll D, Jenkinson C, Reynolds DJ, et al. (1996) Assessing the quality of reports of randomized clinical trials: is blinding necessary? Controlled clinical trials 17: 1-12

2. Wilson DC, Cairns P, Halliday HL, Reid M, McClure G, et al. (1997) Randomised controlled trial of an aggressive nutritional regimen in sick very low birthweight infants. Arch Dis Child Fetal Neonatal Ed 77: F4-11.

3. Javid PJ, Kim HB, Duggan CP, Jaksic T (2005) Serial transverse enteroplasty is associated with successful short-term outcomes in infants with short bowel syndrome. J Pediatr Surg 40: 1019-1023.

4. Leaf A, Dorling J, Kempley S, McCormick K, Mannix P, et al. (2012) Early or delayed enteral feeding for preterm growth-restricted infants: a randomized trial. Pediatrics 129: e1260-1268.
5. Davey AM, Wagner CL, Cox C, Kendig JW (1994) Feeding premature infants while low umbilical artery catheters are in place: a prospective, randomized trial. J Pediatr 124: 795-799.

6. Ibrahim HM, Jeroudi MA, Baier RJ, Dhanireddy R, Krouskop RW (2004) Aggressive early total parental nutrition in low-birth-weight infants. J Perinatol 24: $482-486$

7. Brownlee KG, Kelly EJ, Ng PC, Kendall-Smith SC, Dear PR (1993) Early or late parenteral nutrition for the sick preterm infant? Arch Dis Child 69: 281-283.

8. Blanco CL, Falck A, Green BK, Cornell JE, Gong AK (2008) Metabolic responses to early and high protein supplementation in a randomized tria evaluating the prevention of hyperkalemia in extremely low birth weight infants. J Pediatr 153: 535-540.

9. Blanco CL, Gong AK, Green BK, Falck A, Schoolfield J,et al. (2011) Early changes in plasma amino acid concentrations during aggressive nutritional therapy in extremely low birth weight infants. J Pediatr 158:5 43-548.

10. Blanco CL, Gong AK, Schoolfield J, Green BK, Daniels W, et al. (2012) Impact of early and high amino acid supplementation on ELBW infants at 2 years. J Pediatr Gastroenterol Nutr 54: 601-607.

11. Valentine CJ, Fernandez S, Rogers LK, Gulati P, Hayes J, et al. (2009) Early amino-acid administration improves preterm infant weight. J Perinatol 29: 428432

12. Kotsopoulos K, Benadiba-Torch A, Cuddy A, Shah PS (1991) Safety and efficacy of early amino acids in preterm, 28 weeks gestation. J Perinatol 12 : 749-754.

13. Gilbertson N, Kovar IZ, Cox DJ, Crowe L, Palmer NT (1991) Introduction of intravenous lipid administration on the first day of life in the very low birth weight neonate. J Pediatr 119: 615-623.

14. Sosenko IR, Rodriguez-Pierce M, Bancalari E (1993) Effect of early initiation of intravenous lipid administration on the incidence and severity of chronic lung disease in premature infants. J Pediatr 123: 975-982.

15. Deshpande G, Simmer K (2011) Lipids for parenteral nutrition in neonates. Curr Opin Clin Nutr Metab Care 14: 145-150.

16. Gura KM, Parsons SK, Bechard LJ, Henderson T, Dorsey M, Phipatanakul $W$, et al. (2005) Use of a fish oil-based lipid emulsion to treat essential fatty acid deficiency in a soy allergic patient receiving parenteral nutrition. Clinica nutrition 24: 839-847.

17. Antébi H, Mansoor O, Ferrier C, Tétégan M, Morvan C, et al. (2004) Liver function and plasma antioxidant status in intensive care unit patients requiring total parenteral nutrition: comparison of 2 fat emulsions. JPEN J Parenter Enteral Nutr 28: 142-148.

18. Wu PA, Kerner JA, Berquist WE (2006) Parenteral nutrition-associated cholestasis related to parental care. Nutr Clin Pract 21: 291-295.

19. Wanten GJ, Calder PC (2007) Immune modulation by parenteral lipid emulsions. Am J Clin Nutr 85: 1171-1184.

20. Beath SV, Davies P, Papadopoulou A, Khan AR, Buick RG, et al. (1996) Parenteral nutrition-related cholestasis in postsurgical neonates: multivariate analysis of risk factors. J Pediatr Surg 31: 604-606.

21. Modi BP, Langer M, Ching YA, Valim C, Waterford SD, et al. (2008) Improved survival in a multidisciplinary short bowel syndrome program. J Pediatr Surg 43: $20-24$

22. Diamond IR, Pencharz PB, Wales PW (2009) What is the current role for parenteral lipid emulsions containing omega- 3 fatty acids in infants with shor bowel syndrome? Minerva Pediatr 61: 263-272.

23. DeLegge M, Alsolaiman MM, Barbour E, Bassas S, Siddiqi MF, et al. (2007) Short bowel syndrome: parenteral nutrition versus intestinal transplantation. Where are we today? Dig Dis Sci 52: 876-892.

24. Cavicchi M, Crenn P, Beau P, Degott C, Boutron MC, et al. (1998) Severe live complications associated with long-term parenteral nutrition are dependent on lipid parenteral input. Transplant Proc 30: 2547.

25. Fallon EM, Le HD, Puder M (2010) Prevention of parenteral nutrition-associated liver disease: role of omega-3 fish oil. Curr Opin Organ Transplant 15: 334-340.

26. Lehner F, Demmelmair H, Röschinger W, Decsi T, Szász M, et al. (2006) Metabolic effects of intravenous LCT or MCT/LCT lipid emulsions in preterm infants. J Lipid Res 47: 404-411. 
Citation: Kotiya P, Zhu X (2015) Effects of Early and Late Parenteral Nutrition on Clinical Outcomes in Very Low Birth Weight Preterm Infants: A Systematic Review and Meta-analysis. J Neonatal Biol 4: 191. doi:10.4172/2167-0897.1000191

Pge 7 of 7

27. Casey L, Lee KH, Rosychuk R, Turner J, Huynh HQ (2008) 10-year review of pediatric intestinal failure: clinical factors associated with outcome. Nutr Clin Pract 23: 436-442.

28. Pawlik D, Lauterbach R, Turyk E (2011) Fish-oil fat emulsion supplementation may reduce the risk of severe retinopathy in VLBW infants. Pediatrics 127 : 223-228.

29. Calder PC (2006) n-3 polyunsaturated fatty acids, inflammation, and inflammatory diseases. Am J Clin Nutr 83: 1505S-1519S.
30. Moher D, Liberati A, Tetzlaff J, Altman DG (2009) Preferred reporting items for systematic reviews and meta-analyses: the PRISMA statement. PLoS medicine 4: 264-269.

31. Mercer JS, Vohr BR, McGrath MM, Padbury JF, Wallach M, et al. (2006) Delayed cord clamping in very preterm infants reduces the incidence of intraventricular hemorrhage and late-onset sepsis: a randomized, controlled trial. Pediatrics 117: 1235-1242. 